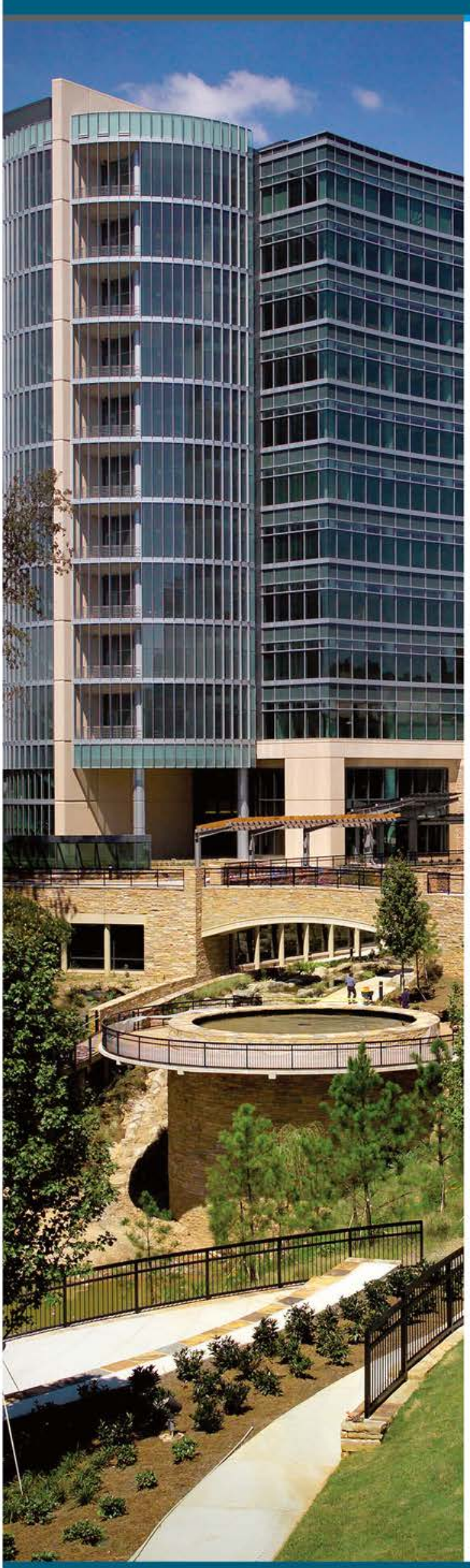

\title{
Evaluation of Side Stream Filtration Technology at Oak Ridge National
} Laboratory

Prepared for the U.S. Department of Energy Federal Energy Management Program

August 2014

\section{FEMPillis




\section{Contacts}

Saralyn Bunch

Federal Energy Management Program

US Department of Energy

1000 Independence Ave, SW

Washington, DC 20585-0121

Phone: (202) 586-3267

E-mail: saralyn.bunch@ee.doe.gov

Brian Boyd

Pacific Northwest National Laboratory

902 Battelle Boulevard

Richland, WA 99352

Phone: (509) 371-6724

E-mail: brian.boyd@pnnl.gov

Craig Smith

Central Utilities Team Leader

Spallation Neutron Source

Oak Ridge National Laboratory

P.O. Box 2008, Bethel Valley Road

Bldg. 8600, Rm. B-174, MS 6485

Oak Ridge, TN 37831

Phone: (865) 576-1149

Email: smithcc1@ornl.gov 


\section{Acknowledgements}

Technical assistance and expertise, as well as production assistance, was provided by the following PNNL staff:

Kate McMordie Stoughton

Jennifer Williamson

Erica Johnson

James Cabe

Matt Wilburn 


\section{Abbreviations and Acronyms}

Btu British thermal unit

$\mathrm{kW}$

kilowatt

MMBtu

million British thermal units

ORNL

Oak Ridge National Laboratory

PNNL

Pacific Northwest Nation Laboratory

SNS

Spallation Neutron Source 


\section{Contents}

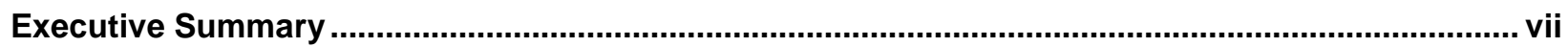

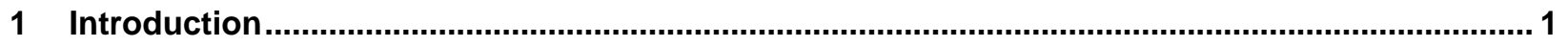

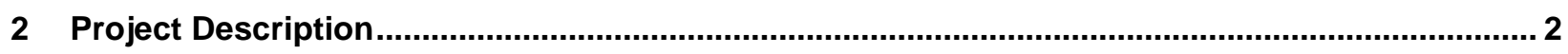

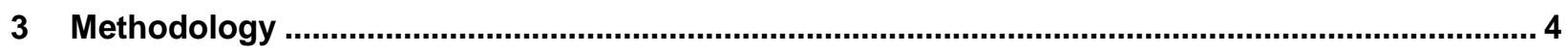

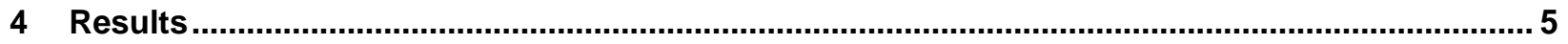

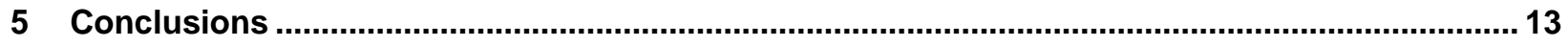

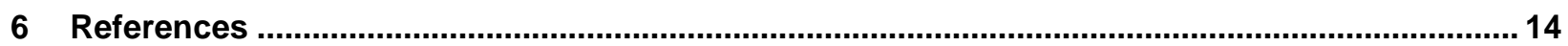




\section{List of Figures}

Figure 1. Cooling Tower with Side Stream Filtration Examples.................................................... 1

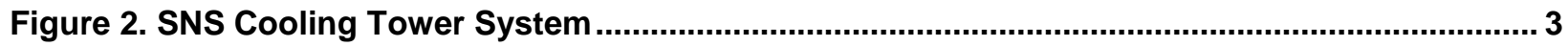

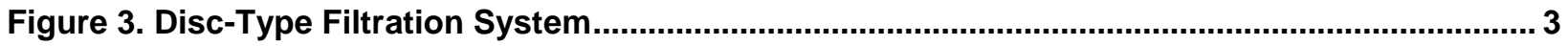

Figure 4. Energy Use Comparison for Accelerator and Condenser ................................................ 5

Figure 5. Water Use Comparison for Accelerator and Condenser ..................................................... 6

Figure 6. Chemical Use Comparison for Accelerator and Condenser ........................................... 7

Figure 7. Daily Heat Rejection for the Accelerator and Condenser .................................................. 8

Figure 8. Normalized Energy Use for the Accelerator and Condenser ............................................ 9

Figure 9. Normalized Water Use for the Accelerator and Condenser ............................................ 10

Figure 10. Normalized Chemical Use for the Accelerator and Condenser ......................................11 


\section{List of Tables}

Table 1. Comparison of Accelerator and Condenser Systems …................................................ 12

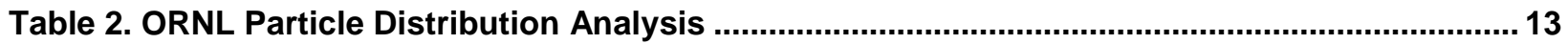




\section{Executive Summary}

This technology evaluation was performed by Pacific Northwest National Laboratory and Oak Ridge National Laboratory on behalf of the Federal Energy Management Program. The objective was to quantify the benefits side stream filtration provides to a cooling tower system.

The evaluation assessed the performance of an existing side stream filtration system at a cooling tower system at Oak Ridge National Laboratory’s Spallation Neutron Source research facility. This location was selected because it offered the opportunity for a side-by-side comparison of a system featuring side stream filtration and an unfiltered system. Both systems operate in the same ambient conditions, receive supply water from the same source, have the same control parameters, and have the same treatment programs. Both are managed by a utility software program that controls system performance and monitors and stores various operating conditions. The program allowed for abundant historical data to be downloaded and analyzed, establishing energy and water use comparisons; however, data predating installation of the side stream filtration technology was not available, so recent data comparing the two systems was used for the analysis. To quantify the performance of both the filtered and the unfiltered systems, the evaluation process also looked at particle analysis, daily chemical consumption, maintenance history, and information gathered from discussions with the facility engineers. Despite the similarities between the two systems, the disparity in the cooling requirements and fundamental operations of each system required the energy, water, and chemical use to be normalized by each system's heat rejection to attempt to account for these differences.

The results of the evaluation show the side stream filtration system is achieving its intended purpose by reducing total suspended solids by $99 \%$ compared to the unfiltered system. As expected, this is resulting in a $17 \%$ reduction in chemical use per million British thermal units of heat rejected and $80 \%$ less maintenance time annually to clean the basin of the filtered system. On the other hand, side stream filtration is not showing a positive impact in energy and water use in this application. The system with side stream filtration is using an average of $204 \%$ more energy and $16 \%$ more water per million British thermal units of heat rejection than the system that is unfiltered.

The disparity is unrelated to the side stream filtration system but rather is a result of the inherent operational differences between the two cooling systems to meet their respective cooling demands, which was uncovered in the evaluation. The filtered system has a much larger cooling load that requires significantly more energy to operate the recirculation pumps and cooling tower fans as explained by the pump and fan affinity laws ${ }^{1}$. The disparity in energy and water use is not tied to the side stream filtration as its energy use is negligible compared to the recirculation pumps and cooling tower fans and it only uses a small amount of water during the backwash cycle, which is also negligible compared to the water losses due to evaporation and blowdown associated with a properly operating cooling tower system. Further analysis would be required

\footnotetext{
${ }^{1}$ The affinity laws explain the relationship between variables in pump and fan performance related to pump power and speed. For more information on pump affinity laws go to www.engineeringtoolbox.com/affinity-lawsd 408.html and for more information on fan affinity laws go to www.engineeringtoolbox.com/fan-affinity-lawsd_196.html.
} 
to comparatively quantify the energy and water use in this case as all the fans and pumps are controlled by variable frequency drive controlled motors.

Based on the results of this evaluation, we can conclude the following:

- The side stream filtration system is achieving its intended purpose.

- The normalized data shows the system using side stream filtration has lower chemical consumption, resulting in less annual maintenance. 


\section{Introduction}

Side stream filtration systems continuously filter a portion of the cooling water to remove debris and particles and return filtered water to the cooling tower basin (called the sump). Figure 1 shows a simplified cooling tower schematic, including the two example locations where side stream filtration typically can be installed. These systems continuously remove suspended solids, organics, and silt particles for a portion of the water system, reducing the likelihood of fouling and bio growth, which helps to control other issues in the system such as scaling and corrosion. This improves system efficiency and often reduces the amount of water that is rejected from the system, called blowdown. There are a variety of filter types, which generally fall into four basic categories: screen filters, centrifugal filters, sand filters, and multi-media filters (WPCP 2012).

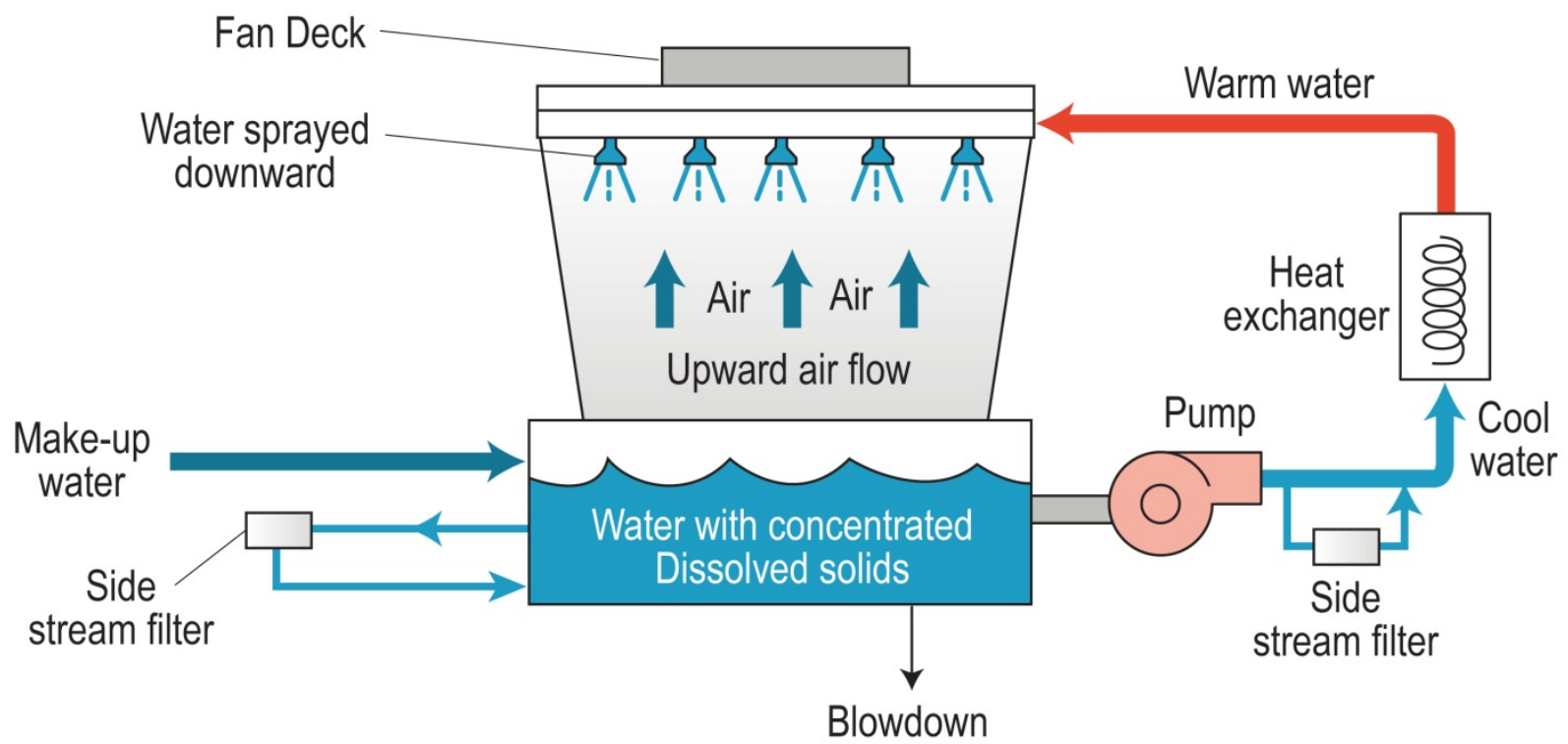

Figure 1. Cooling Tower with Side Stream Filtration Examples

For this evaluation, a side stream filtration system was evaluated at Oak Ridge National Laboratory (ORNL) to try to quantify the benefits the system provides to a cooling tower system. Side stream filtration reduces cost and may increase water and energy efficiency, as described below (Latzer 2012; BAC 2012).

- Reduction in water consumption: Demand for makeup water in cooling towers is decreased with an increase in the system's cycles of concentration. Essentially, higher cycles of concentration mean that water is being recirculated through the system longer before blowdown is required. Less blowdown reduces the amount of makeup water required in the system, resulting in water savings.

- Reduction in energy consumption: Side stream filtration reduces the likelihood of scale and fouling on the heat exchangers. Even the smallest layer of scale or fouling on heat exchange surfaces can reduce the rate of heat exchange, forcing the system to work harder to achieve the desired cooling and in turn increasing energy costs. 
- Reduction in chemical use: Chemicals are used to bind suspended particles in the water stream and prevent scaling and corrosion. Dirty water requires more chemicals than clean water because a buildup of solid contaminants provides a buffer that reduces the effects of treatment chemicals. A side stream filtration system can remove suspended particles, reducing the need for additional chemical treatments such as dispersants and biocides.

- Lower maintenance cost: Traditionally, cooling towers are cleaned by draining the tower and having the sediment removed mechanically or manually from the sump. Costs associated with the cleaning process include downtime, labor, lost water, and additional chemicals. Cooling systems that are cleaned via side stream filtration routinely provide longer periods of continuous operation before being taken offline for required maintenance.

- Improvement in productivity and reduction in downtime: When a cooling system is fouled or has scale buildup, production may be slowed due to inefficient heat exchange equipment. In some cases, the cooling system and heat exchange equipment may need to be taken offline for repairs, decreasing production.

- Control of biological growth: Biological growth control and reduction can mitigate potential health problems, such as those caused by Legionella. ASHRAE Guideline 122000 has basic treatment recommendations for control and prevention, stating that the key to success is system cleanliness. Legionella thrives where there are nutrients to aid its growth and surfaces on which to live. Use of side stream filtration can minimize habitat surfaces and nutrients by maintaining lower particle levels in the water stream.

\section{Project Description}

Located in the Eastern Tennessee Valley, ORNL is a multi-disciplinary science and technology laboratory with a staff of over 5,700 focusing on innovation in clean energy, nuclear security, materials, computational, and neutron science and technology. ORNL houses an acceleratedbased neutron source, called the Spallation Neutron Source (SNS), which provides pulsed neutron beams for research in material sciences.

The SNS facility features a four-cell cooling tower that was commissioned in 2003. Two cells of the cooling tower are dedicated to process cooling for the accelerator (the accelerator side) and two cells are dedicated to comfort cooling (the condenser side) for approximately 700,000 square feet of office space associated with SNS (Figure 2). Each cell features a mechanical draft fan at the top of the structure that's connected to a 150-horsepower motor. The condenser side water is circulated by four 250-horsepower driven pumps to the chillers that provide comfort cooling for the building space, and the accelerator side water is circulated by four 350-horsepower driven pumps to the heat exchangers associated with the accelerator. All of the pumps and fans feature variable frequency drives. 


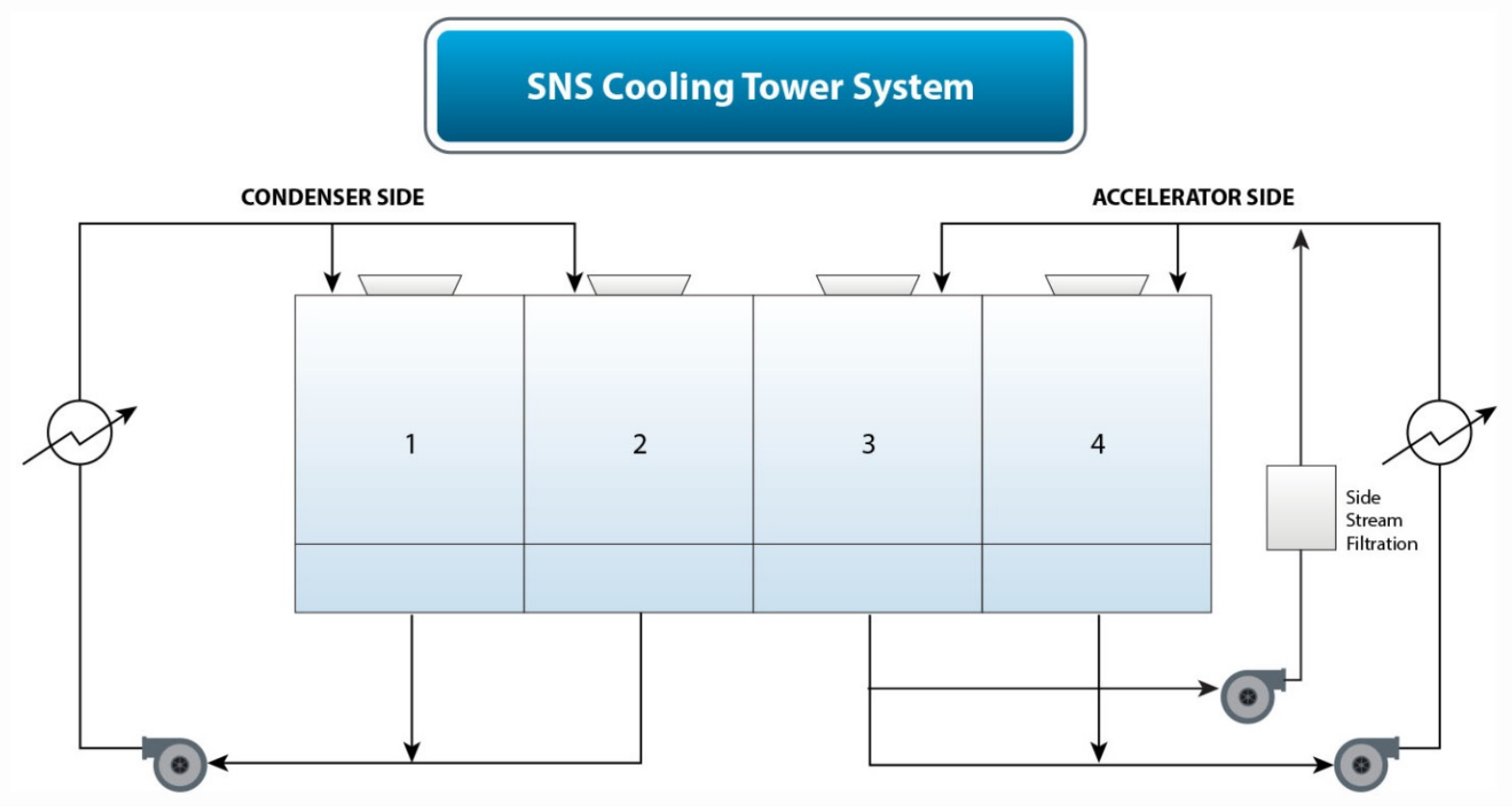

Figure 2. SNS Cooling Tower System

In 2007 a disc-type filtration system (see Figure 3) was installed on the accelerator side to meet strict water quality requirements for suspended solids.

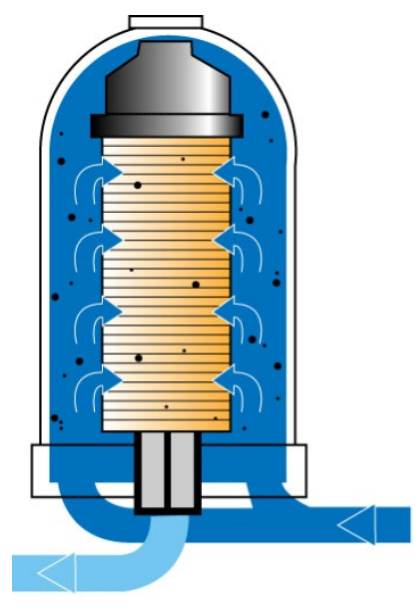

FILTRATION PROCESS

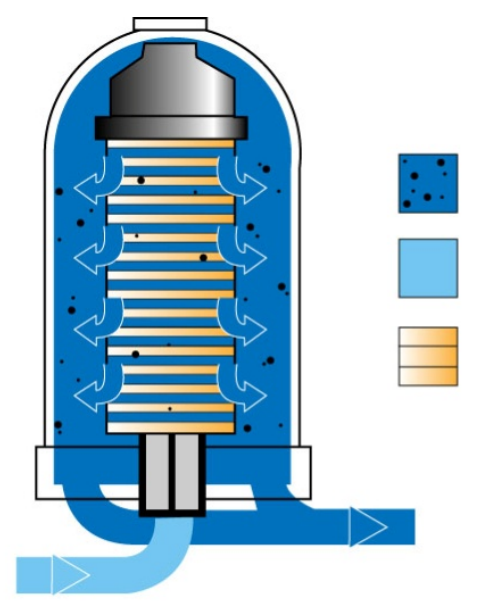

\section{BACKFLUSH PROCESS}

Figure 3. Disc-Type Filtration System

This technology uses plastic discs made of polypropylene that are stacked together under pressure and grooved to filter particles of specific micron sizes. Each disc has etched grooves in a slightly different pattern array between the top and bottom of the disc. When multiple discs are stacked and centered on a skeletal cylindrical structure, called a "spine," the discs form a hollow cylinder with the ends of the grooves exposed to both the inside and the outside surfaces of the cylinder. The different groove patterns of the stacked discs create intersections of different sizes 
to trap particles when cooling water passes from the outside to the inside of the hollow cylinder. As particles are captured within the depth of the disc stack, a pressure differential is created. Backwash is initiated when the preset pressure differential is achieved. The stack pressure is relieved and the filtered water is forced through the disc stack in reverse through several nozzles within the disc stack spine.

Disc filters can remove both solids and organic particles effectively. These filters also use much less water than other types of self-cleaning filters for backwash cycles, and tend to have relatively lower installation and operating costs compared to other filters with equivalent filtration rates. Disc filters can backflush multiple filters sequentially, and because the backflush cycle is sequential, the filtration process is seldom interrupted. Triggered by differential pressures or timing intervals, or a combination of both, the self-cleaning process is fully automatic, requiring little maintenance.

The cooling tower system at SNS was chosen for the evaluation of side stream filtration because the technology is already used on two of the four cooling tower cells, allowing for a side-by-side comparison of the filtered versus unfiltered system performance. Several critical operational parameters are also equivalent as both sides of the system experience the same ambient conditions; they receive supply water from the same source and the chemical treatments and control platforms are the same. Additionally, the site features a central utility monitoring system that tracks energy use, water use, and system performance on both sides of the cooling tower. The one significant drawback is that the cooling load is quite different for the two sides of the system. Therefore, a direct comparison of energy use, water use, and chemical consumption wouldn't accurately quantify the impact of the filtration system. To account for this key difference, data was normalized against the heat rejection rate to draw conclusions on side stream filtration effectiveness (described below).

\section{Methodology}

To quantify the performance of both sides of the system, the following data was collected:

- 30-minute interval energy consumption for the fans and recirculation pumps from November 18, 2012 through September 30, 2013

- daily chemical consumption for each system from November 18, 2012 through September 30, 2013

- daily metered water consumption for both systems from November 18, 2012 through September 30, 2013

- particle analysis on water samples for each side of the system

- historical weather data

- hourly interval recirculation rates for both sides from November 18, 2012 through September 30, 2013

- hourly interval supply and return temperatures for each side from November 18, 2012 through September 30, 2013

- annual maintenance requirements for cleaning the basins on each side 
Because the cooling requirements are not the same for the condenser side and accelerator side of the system, energy use, water use, and chemical use were all normalized against the heat rejection rate (measured in British thermal units (Btu)), which was determined using the following calculation:

$\mathrm{h}=\mathrm{Cp} \times \rho \times \mathrm{q} \times \Delta \mathrm{T}$

where:

$\mathrm{h}=$ heat rejected

$\mathrm{Cp}=1\left(\mathrm{Btu} / \mathrm{lb}{ }^{\circ} \mathrm{F}\right)$ for water

$\mathrm{p}=8.33(\mathrm{lb} / \mathrm{gal})$ for water

$\mathrm{q}=$ water flow rate $(\mathrm{gal} / \mathrm{min})$

$\Delta \mathrm{T}=$ return temperature - supply temperature $\left({ }^{\circ} \mathrm{F}\right)$

\section{Results}

The non-normalized energy use of the fans and recirculation pumps for each side of the system (Figure 4) shows the accelerator side uses significantly more energy for the majority of the year to meet the process cooling needs associated with SNS research while the condenser side, as expected, has a seasonal rise in use during the hot summer months. It's important to note, the energy use for the accelerator side are not elevated because of the side stream filtration system. The pumps and fans in that system use significantly more energy to meet the cooling needs of the accelerator compared the condenser tower system.

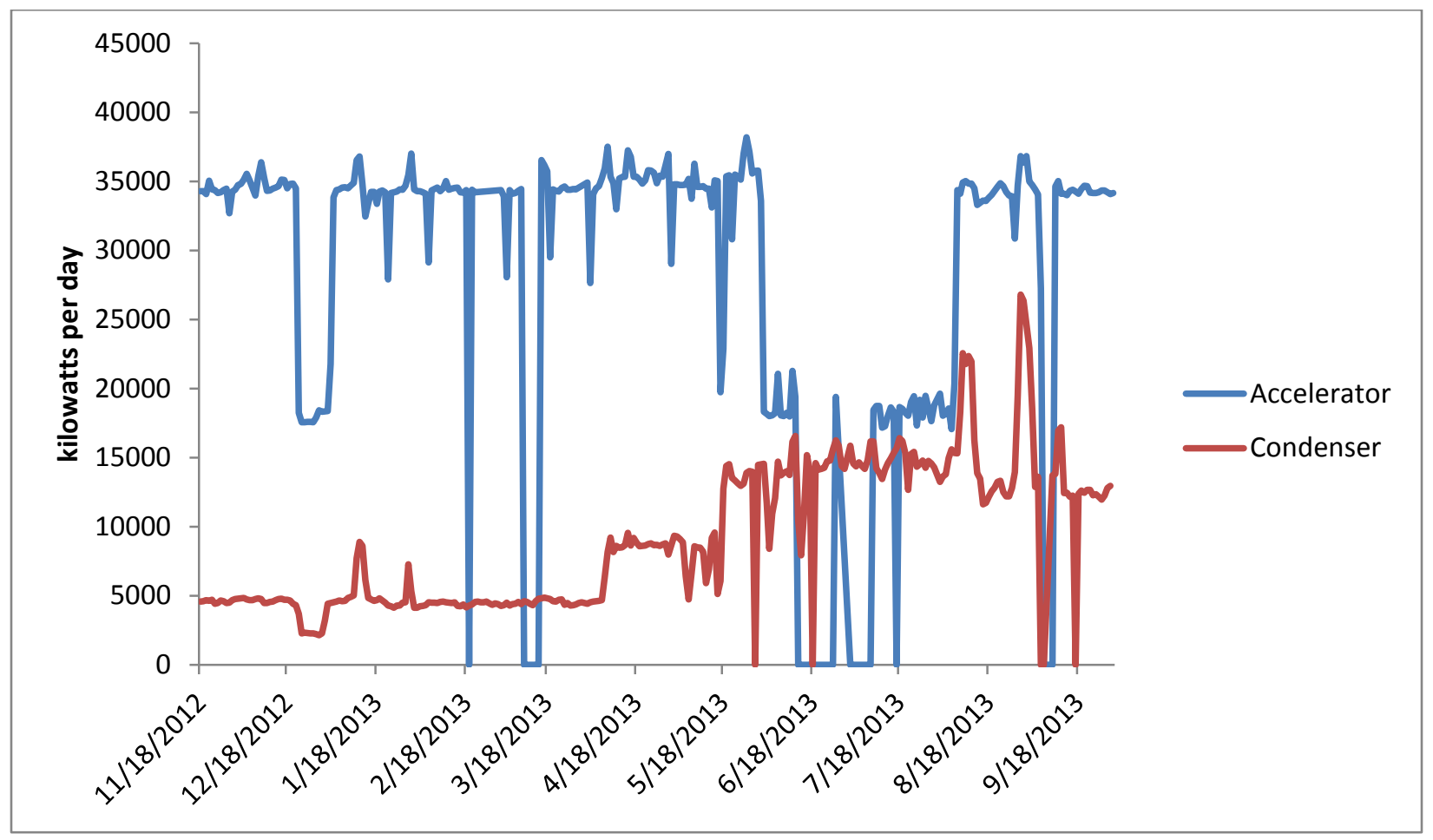

Figure 4. Energy Use Comparison for Accelerator and Condenser 
Similarly, the makeup water use for the same period shows the accelerator consumes more water throughout the year (Figure 5). The difference between the water use of the two systems and the energy use is less substantial. In addition, there is more seasonal variation in energy use than in metered water use. Again, it is important to note the makeup requirements for the accelerator system are not negatively impacted by the side stream filtration system as it doesn't consume any water. It only uses a very small amount of water during its backwash cycle which will be negligible compared to the water losses of each system due to evaporation and blowdown.

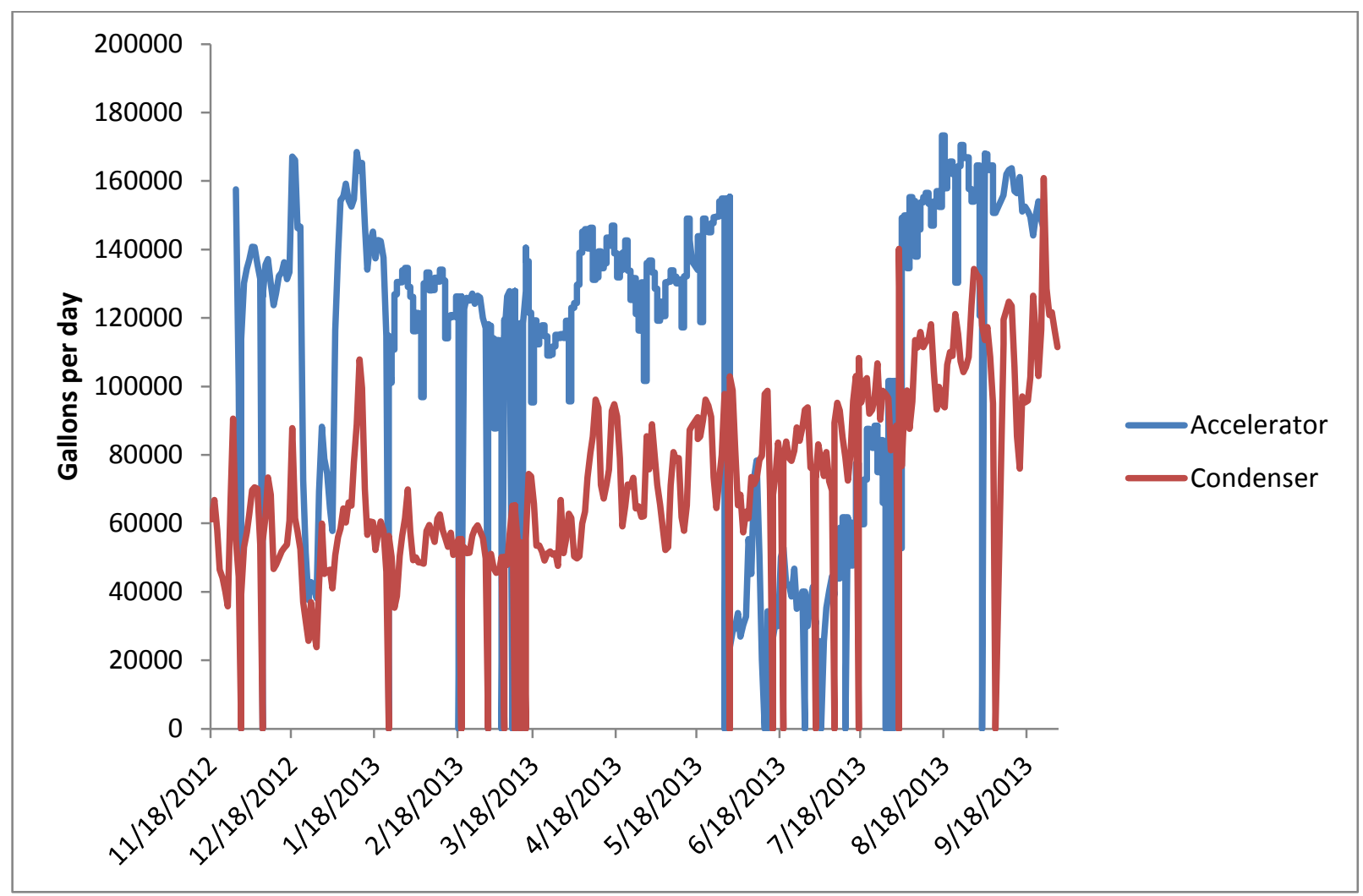

Figure 5. Water Use Comparison for Accelerator and Condenser 
Chemical use shows both systems used about the same amount of product on the days for which data is available during the period analyzed (Figure 6). Data wasn't available for the condenser side for most of the last half of the analysis period. These results start to show the impact of side stream filtration as the reduced amount of suspended solids requires less dispersant to control fouling.

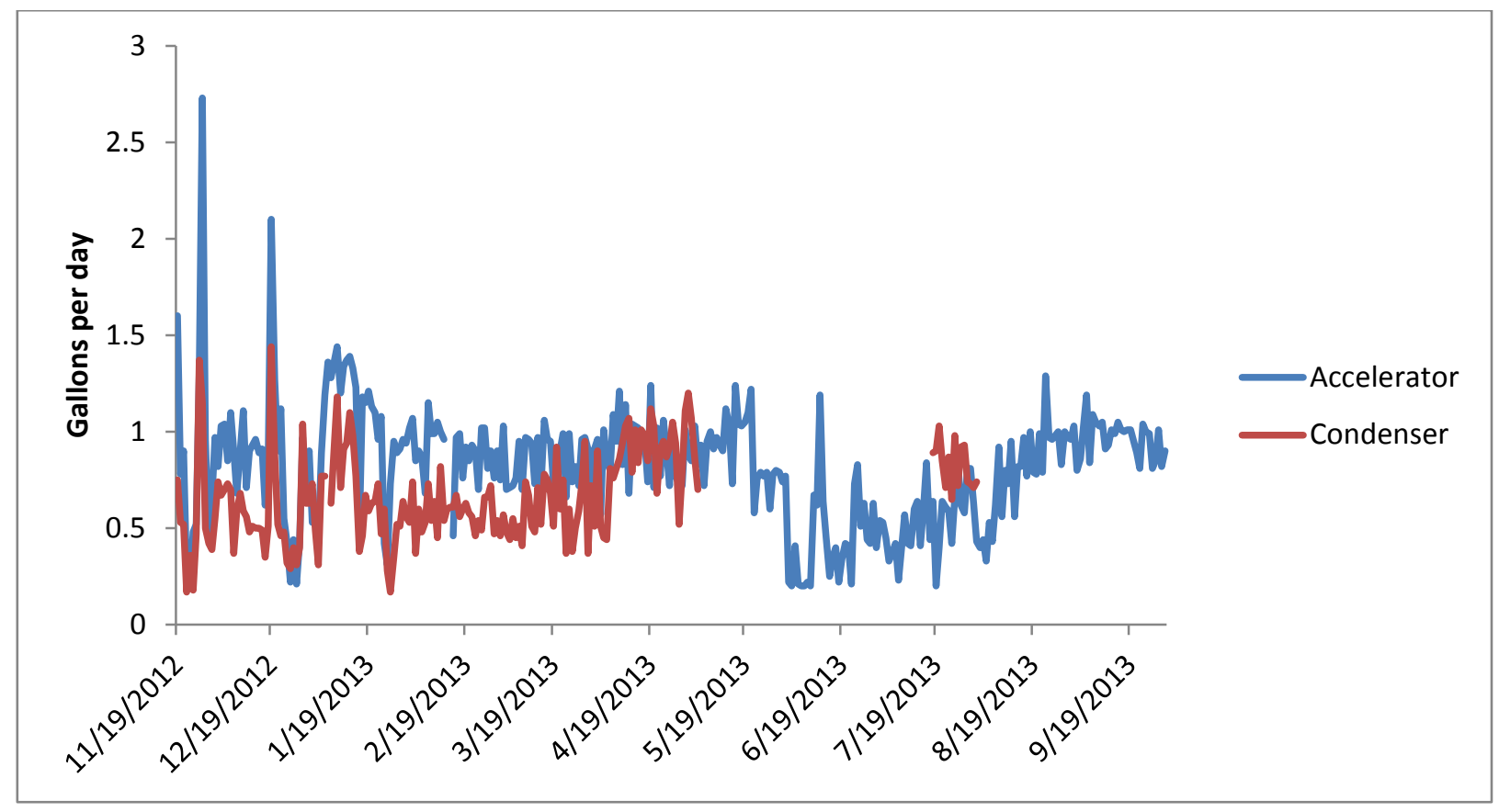

Figure 6. Chemical Use Comparison for Accelerator and Condenser 
Because of the disparate cooling requirement, it was determined that the relative comparison of the filtered side versus the unfiltered side would need to be normalized against the heat rejection. Daily heat rejection was calculated using hourly interval recirculation rates and temperature change for each system. The heat rejection is higher for the accelerator for the majority of the year with only a short period during the summer where the condenser system heat rejection matches or exceeds the accelerator (Figure 7). Note that the accelerator was offline for several weeks from the end of May to the middle of July. For that period, the data was omitted to avoid skewing the results.

When the accelerator is in operation, the accelerator side of the system's heat rejection averaged just over 890 million British thermal units (MMBtu) per day. The condenser side's heat rejection averaged about 602 MMBtu per day for the analysis period.

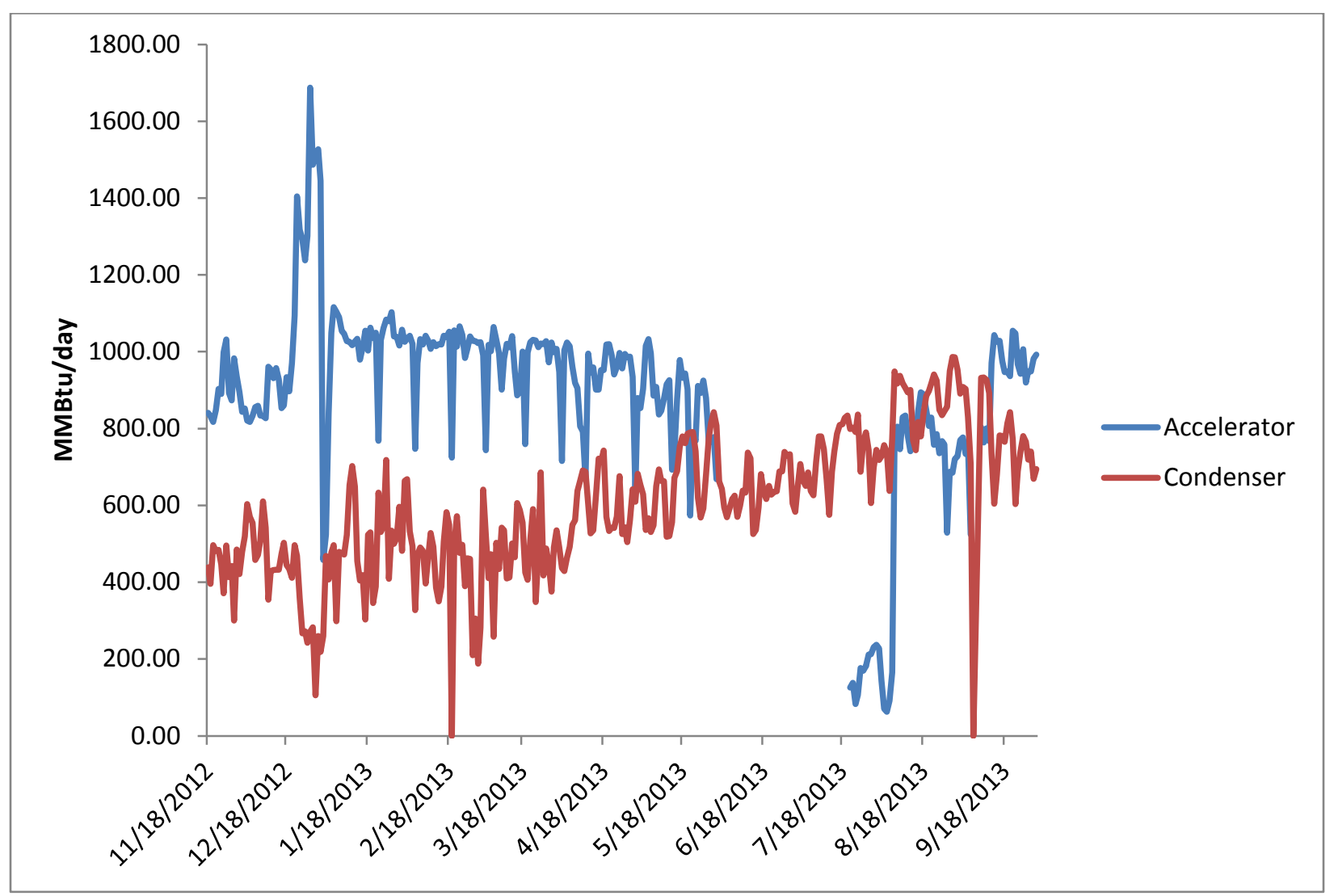

Figure 7. Daily Heat Rejection for the Accelerator and Condenser

The normalized energy use in terms of rate of energy use per heat rejection in kilowatts per million Btu (kW/MMBtu) for both systems shows the filtered accelerator side consistently uses more energy than the non-filtered condenser side (Figure 8). On average, the accelerator side used $44.05 \mathrm{~kW} / \mathrm{MMBtu}$ while the accelerator was in operation and the condenser side used 14.47 kW/MMBtu during the analysis period. The higher energy use on the accelerator side is not attributed to the side stream filtration system as its energy consumption is negligible compared to the recirculation pumps and cooling tower fans. Rather, the disparity points to operational differences between the two cooling tower systems to meet their respective cooling demands which are explained by the pump and fan affinity laws. Analysis beyond the scope and 
budget of this project would be needed to accurately quantify the energy use benefit of the side stream filtration system by comparing these two systems.

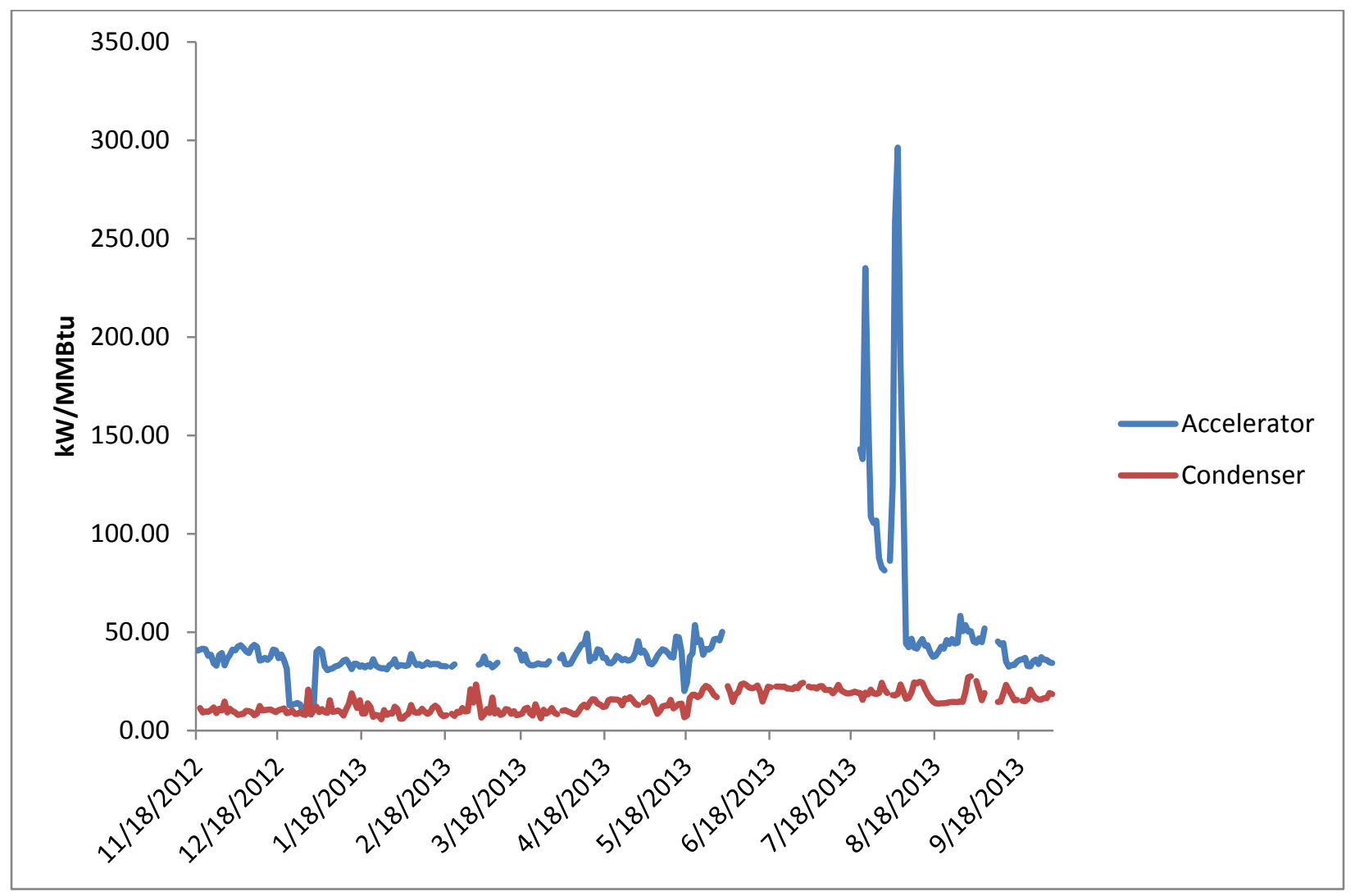

Figure 8. Normalized Energy Use for the Accelerator and Condenser 
The normalized water use, or water use per million Btu of heat rejection (gal/MMBtu), also shows the accelerator side of the system used more water than the condenser side (Figure 9). On average, the filtered system used $145.43 \mathrm{gal} / \mathrm{MMBtu}$ while the non-filtered side used $125.53 \mathrm{gal} / \mathrm{MMBtu}$ during the analysis period. Similar to the energy use results, though to a lesser degree, the water use comparison reveals more about the operational differences of the two systems rather than the quantifiable resource benefits of side stream filtration.

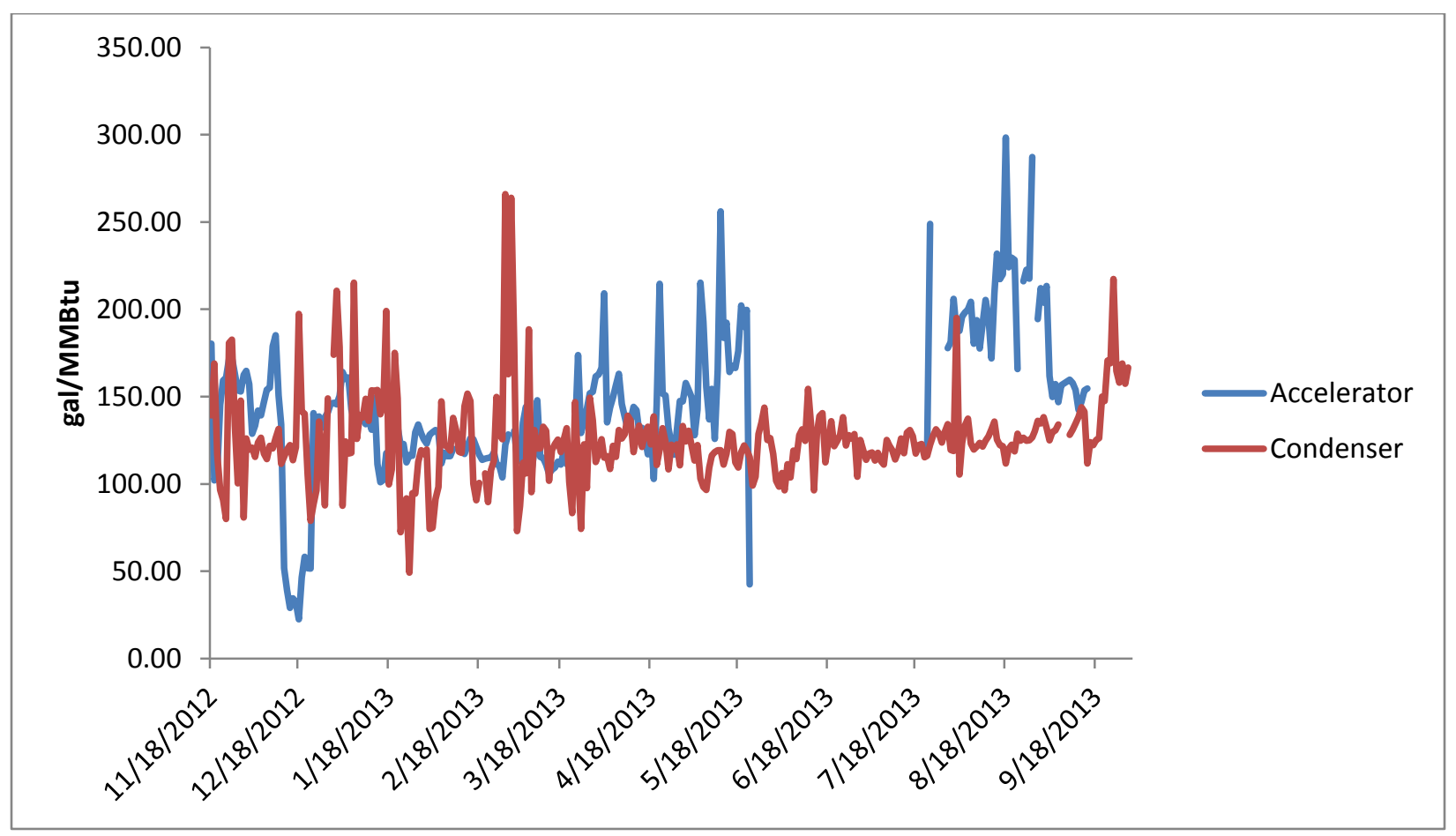

Figure 9. Normalized Water Use for the Accelerator and Condenser 
Normalized chemical use, or gallons of chemical used per million Btu of heat rejection (gal/MMBtu), shows the positive impact of side stream filtration at this location as the accelerator side is using less chemical than the condenser side of the system (Figure 10). During the analysis period, the filtered accelerator side used $0.0012 \mathrm{gal} / \mathrm{MMBtu}$ while the condenser side used $0.0014 \mathrm{gal} / \mathrm{MMBtu}$.

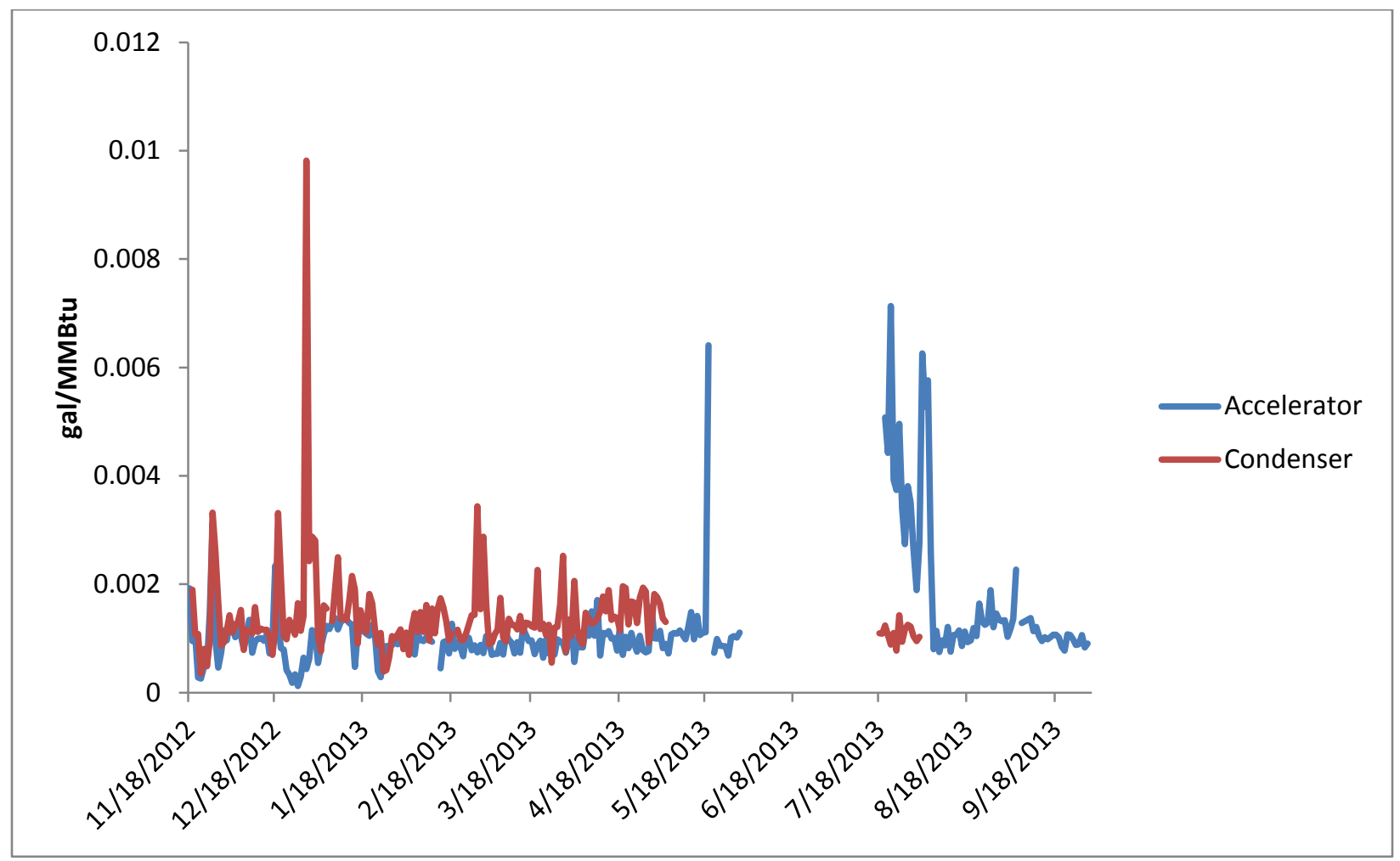

Figure 10. Normalized Chemical Use for the Accelerator and Condenser 
Table 1 compares the annual averages of the accelerator and the condenser systems and the percent difference between the two systems of the normalized rate of energy use, water use, and chemical use for both systems from November 18, 2012 to September 30, 2013.

Table 1. Comparison of Accelerator and Condenser Systems

\begin{tabular}{l|c|c|c}
\hline & $\begin{array}{c}\text { Accelerator } \\
(\mathrm{kW} / \mathrm{MMBtu})\end{array}$ & $\begin{array}{c}\text { Condenser } \\
(\mathrm{kW} / \mathrm{MMBtu})\end{array}$ & $\begin{array}{c}\text { Percent Difference of } \\
\text { the Two Systems }\end{array}$ \\
\hline Energy Use & $\begin{array}{c}44.05 \\
\text { Accelerator } \\
\text { (gal/MMBtu) }\end{array}$ & $\begin{array}{c}\text { Condenser } \\
\text { (gal/MMBtu) }\end{array}$ & $\begin{array}{c}\text { Percent Difference of } \\
\text { the Two Systems }\end{array}$ \\
\hline Water Use & 145.43 & 125.53 & $16 \%$ \\
\hline Chemical Use & $\begin{array}{c}\text { Accelerator } \\
\text { (gal/MMBtu) }\end{array}$ & $\begin{array}{c}\text { Condenser } \\
\text { (gal/MMBtu) }\end{array}$ & $\begin{array}{c}\text { Percent Difference of } \\
\text { the Two Systems }\end{array}$ \\
\hline
\end{tabular}

As expected, the accelerator side with filtration uses less chemical when normalized for the heat rejection rate. On the other hand, the filtered side is using more energy and water even when the numbers are normalized with the heat rejection rate. This may be the result of the inherent operational differences between the two cooling systems or subtle differences in the control parameters between the two systems that may not otherwise be evident.

Additional factors were also considered to attempt to measure the performance benefits from the filtration system. In terms of maintenance costs, both systems are taken offline and cleaned twice a year. Significantly more effort is required to clean out the basin on the non-filtered condenser side of the system compared with the filtered accelerator side. Specifically, it takes about two and a half days for a vacuum truck to clean out the sludge that develops in the basin on the non-filtered condenser side, while on the filtered accelerator side it only takes about half a day, or $80 \%$ less time annually in maintenance requirements. 
Lastly, particulate analysis shows the filter is performing correctly. Table 2 compares the overall particle volume for both the system with side stream filtration and the system without. The table shows particle volume, measured in cubic millimeters per one hundred liters $\left(\mathrm{mm}^{3} / 100 \mathrm{~L}\right)$. The total particle volume of the system without side stream filtration is 3,986 $\mathrm{mm}^{3} / 100 \mathrm{~L}$ while the particle volume in the filtered side is reduced to only $43 \mathrm{~mm}^{3} / 100 \mathrm{~L}$. This represents a $99 \%$ reduction in suspended solids, including complete removal of particles larger than 80 microns.

Table 2. ORNL Particle Distribution Analysis

\begin{tabular}{|c|c|c|c|c|}
\hline Micron Range & $\begin{array}{c}\text { Particle Volume } \\
\text { without Side Stream } \\
\text { Filtration } \\
\left(\mathrm{mm}^{3} / 100 \mathrm{~L}\right)\end{array}$ & $\begin{array}{l}\text { Percentage of } \\
\text { Overall Particle } \\
\text { Volume without } \\
\text { Side Stream } \\
\text { Filtration }\end{array}$ & $\begin{array}{c}\text { Particle Volume } \\
\text { with Side Stream } \\
\text { Filtration } \\
\left(\mathrm{mm}^{3} / 100 \mathrm{~L}\right)\end{array}$ & $\begin{array}{l}\text { Percentage of } \\
\text { Overall Particle } \\
\text { Volume with Side } \\
\text { Stream Filtration }\end{array}$ \\
\hline $0.5-1.0$ & 45 & 1.1 & 3 & 6.5 \\
\hline $1.0-5.0$ & 95 & 2.4 & 8 & 17.3 \\
\hline $5.0-10$ & 302 & 7.6 & 7 & 15.7 \\
\hline $10-15$ & 442 & 11.1 & 5 & 11.3 \\
\hline $15-20$ & 553 & 13.9 & 4 & 10.1 \\
\hline $20-30$ & 1,018 & 25.5 & 3 & 6.5 \\
\hline $30-40$ & 575 & 14.4 & 5 & 10.6 \\
\hline $40-50$ & 318 & 8.0 & 3 & 7.1 \\
\hline $50-60$ & 213 & 5.3 & 3 & 7.4 \\
\hline $60-70$ & 178 & 4.5 & 1 & 3.0 \\
\hline $70-80$ & 128 & 3.2 & 2 & 4.6 \\
\hline $80-90$ & 86 & 2.2 & 0 & 0.0 \\
\hline $90-100$ & 34 & 0.9 & 0 & 0.0 \\
\hline Total & 3,986 & & 43 & \\
\hline
\end{tabular}

\section{Conclusions}

The intent of the evaluation was to determine the performance benefits side stream filtration provides to a cooling tower system. The SNS cooling tower system at ORNL was selected because it offered the opportunity for a side-by-side comparison of two systems - one using side stream filtration and the other unfiltered-operating in the same ambient conditions, receiving supply water from the same source, and having the same control parameters and the same treatment programs. In addition, both systems are managed by a utility software program that controls system performance and monitors and stores various meters and probes to measure operating conditions. The program allowed for abundant historical data to be downloaded and analyzed for the evaluation. In addition to the historical data, the evaluation process also looked at particle analysis, daily chemical consumption, maintenance history, and discussions with the facility engineers to quantify the performance of both the filtered and the unfiltered systems.

A key conclusion of the evaluation is that the side stream filtration system is accomplishing its intended purpose at SNS. The particle analysis shows the system is successfully removing much 
of the suspended solids, as was the intent for implementing the technology. It's also greatly reducing the time needed to clean the tower basin every year compared to the non-filtered side. As expected, the reduced levels of suspended solids are resulting in about a 14\% reduction in chemical consumption in gallons used per MMBtu of heat rejected compared to the unfiltered system.

On the other hand, the normalized results show that energy use and water use are statistically higher on the system employing side stream filtration. This is not attributed to the side stream filtration system as its energy use is negligible compared to the recirculation pumps and cooling tower fans and it only uses a small amount of water during the backwash cycle, which is also negligible compared to the water losses due to evaporation and blowdown. After reviewing several layers of data and confirming the operational performance with the SNS facility engineers, the trends over time show statistically that the filtered side uses more water and energy per Btu of heat dissipation. The disparity is unrelated to the side stream filtration system but rather is a result of the inherent operational differences between the two cooling systems to meet their respective cooling demands, which was uncovered in the evaluation. The filtered system has a much larger cooling load that requires significantly more energy to operate the recirculation pumps and cooling tower fans as explained by the pump and fan affinity laws ${ }^{2}$. In this case, the pumps and fans are operated by variable frequency drive controlled pumps making a direct linear comparison of energy and water consumption incomplete. Additional analysis is needed to determine the energy and water benefit provided by the side stream filtration system.

Based on the results of this evaluation, we can conclude the following:

- The side stream filtration system is achieving its intended purpose.

- The normalized data shows the system using side stream filtration has lower chemical consumption, resulting in less annual maintenance.

\section{References}

ASHRAE - American Society of Heating, Refrigeration, and Air-Conditioning Engineers. 2000. Minimizing the Risk of Legionellosis Associated with Building Water Systems. ASHRAE Guideline 12-2000. Atlanta, GA.

BAC - Baltimore Aircoil Company. 2012. Product and Application Handbook 2012. Jessup, MD. http://www.baltimoreaircoil.com/english/resource-library/file/652. Accessed April 2012.

\section{Latzer K. 2012. The Importance of Side Stream Filtration in Water and Energy}

Conservation. Tech Talk. http://www.chemtechwater.ca/attachments/Chemtech\%20Sidestream\%20Techtalk.pdf. Accessed May 2012.

\footnotetext{
${ }^{2}$ The affinity laws explain the relationship between variables in pump and fan performance related to pump power and speed. For more information on pump affinity laws go to www.engineeringtoolbox.com/affinity-lawsd 408.html and for more information on fan affinity laws go to www.engineeringtoolbox.com/fan-affinity-lawsd_196.html.
} 
WPCP - San Jose/Santa Clara Water Pollution Control Plant. 2002. Guidelines for Managing Water in Cooling Systems. San Jose, CA. http://www.sanjoseca.gov/esd/PDFs/cooling.pdf. Accessed April 2012. 
waverater or

For more information, visit

femp.energy.gov

DOE/GO-000000-0000 * Month Year 